\title{
Malignant Hyperthermia: Management Without Dantrolene
}

\author{
Sobia Manzoor, M.D., , Syed Amer Zahoor, M.D., Jan Mohammad Rather M.S. ${ }^{3}$ \\ ${ }^{1,3}$ Senior Residents, ${ }^{2}$ Professor, Cardiac Anaesthesia SKIMS
}

\section{A B S T RA C T}

\begin{abstract}
Malignant Hyperthermia $(\mathrm{MH})$ is a hypermetabolic syndrome which is quite rare in India. Inhalational anesthetics and succinyl choline have been reported as potent triggering agents of $\mathrm{MH}$. Dantrolene remains the gold standard for treating this life threatening syndrome. We encountered a case of malignant hyperthermia in a 34 year old male undergoing ventricular septal defect closure under general anesthesia. We successfully managed our patient by timely recognition of this syndrome and by administering prompt, effective Symptomatic treatment and without dantrolene which was not available in our hospital. JMS 2018; 21 (1):40-43

Key words: Dantrolene, malignant hyperthermia, succinyl choline
\end{abstract}

\section{INTRODUCTION}

Malignant hyperthermia $(\mathrm{MH})$ is a rare condition with very few case reports present in the literature. It is characterized by hyperthermia, hypercarbia, acidosis, tachycardia, muscle rigidity and rhabdomyolysis. The syndrome is triggered in susceptible individuals by potent inhalation agents, succinylcholine, vigorous exercise and heat. We encountered a case of $\mathrm{MH}$ in an adult patient operated for closure of ventricular septal defect. Dantrolene was not available but the patient was successfully managed without any residual morbidity by timely recognition and prompt intervention and aggressive management.

\section{Case report:}

A 34 years old male patient, $70 \mathrm{~kg}$, was scheduled for ventricular septal defect closure. Patient had no previous history of general anesthesia. There was no family history of problems with anesthesia and some of his family members had successfully undergone surgery under general anesthesia without any complication. Neither the patient nor his family members had any history of neuromuscular disease. He had a history of type 2 diabetes mellitus diagnosed 1year back, well controlled on metformin. He was evaluated for exertional dyspnea and diagnosed as

\section{Correspondence}

Dr. Sobia Manzoor M.D.

Senior Resident

Email: Sobiamanzoor1@gmail.com subaortic ventricular septal defect $(10 \mathrm{~mm})$ with severe tricuspid valve regurgitation and mild pulmonary artery hypertension on echocardiogram. His preoperative physical, airway and laboratory examination were within normal limits. On the day of surgery, patient received his usual morning dose of propranolol $12.5 \mathrm{mg}$ with a sip of water. His preoperative vital signs were heart rate: 64 beats/min, blood pressure: $140 / 90 \mathrm{mmHg}$, respiratory rate: 16/min and axillary temperature: $36.7^{\circ} \mathrm{C}$. After securing arterial line under local anesthesia, patient was induced with midazolam $5 \mathrm{mg}$, fentanyl $200 \mathrm{mcg}$, morphine $15 \mathrm{mg}$, vecuronium $8 \mathrm{mg}$ and sevoflurane 5\%. Airway was secured with $8.0 \mathrm{~mm}$ ID ETT. Anesthesia was maintained with oxygen $50 \%$, air $50 \%$ and isoflurane $1 \%$. Right internal jugular vein was cannulated and cvp monitored. About half an hour after induction, patients end tidal carbon dioxide $\left(\mathrm{EtCO}_{2}\right)$ level increased from $40 \mathrm{mmHg}$ to $57 \mathrm{mmHg}$ while $\mathrm{SpO}_{2}$ remained stable. ETCO2 rose further to $70 \mathrm{mmhg}$ and suddenly to $95 \mathrm{mmhg}$. The $\mathrm{CO}_{2}$ absorbent was changed and patient's tidal volume \& respiratory rate were increased in an effort to lower the raised $\mathrm{EtCO}_{2}$. Heart rate remained within normal limits initially but started increasing to 125 130 beats/min while $\mathrm{ETCO}_{2}$ also showed a progressively increasing trend. Hyperventilation was done manually with a separate bain's circuit but it failed to lower down the $\mathrm{ETCO}_{2}$. Chest remained clear and airway pressures were normal. Oropharyngeal temperature also showed a persistent rise to $38.9^{\circ} \mathrm{C}$. Diagnosis of malignant 
hyperthermia was made. Isoflurane was discontinued; another anesthesia machine without any vaporizers was rolled in and attached to the patient. Patient was hyperventilated with 100\% oxygen@10 L/min . Patient was hydrated IV with ice cold normal saline. Gastric and urinary bladder ice cold water lavage was carried out for central cooling. . Peripheral cooling was instituted using cooling fans and ice packs. Esmolol 10mg was administered to control the HR. During the treatment, the highest $\mathrm{ETCO}_{2}$ was $101 \mathrm{mmhg}$ and the highest body temperature was $39^{\circ} \mathrm{C}$. During the next 30 minutes and with active resuscitative measures, the patient's condition gradually stabilized. The $\mathrm{ETCO}_{2}$ decreased to $65 \mathrm{mmh}$ and all vital signs remained within the reference range. Supportive measures were continued. Anaesthesia was maintained using propofol and fentanyl infusions. Continuous monitoring of heart rate, blood pressure, $\mathrm{ETCO}_{2}$, temperature and urine output was carried out. Blood glucose was checked half hourly and insulin infusion was titrated using sliding scale regimen to keep blood glucose levels within normal limits. Blood pressure and heart rate were controlled with inj esmolol. Quick initiation of cardiopulmonary byepass was done. Core hypothermia was induced and maintained throughout the procedure. Peripheral cooling was done by TCU (temperature controlled unit) with particular attention given to urine output, acid- base and electrolyte status.

On bypass, the perfusionist corrected respiratory acidosis by increasing the sweep gas flow rates in the first 30

INTRA OPERATIVE ABG \& ELECTROLYTES

Pre byepass ABG \& electrolytes

\begin{tabular}{|l|l|l|l|l|l|l|l|l|l|l|}
\hline pH & pCO2 & PO2 & HCO3 & Na & K & Ca & Gluc & lactate & SPO2 & Hct \\
\hline 7.22 & 61 & 140 & 25 & 138 & 3.8 & 1.08 & 222 & 3.7 & $99 \%$ & $47 \%$ \\
\hline 7.01 & 110 & 130 & 27.8 & 141 & 3.9 & 1.24 & 215 & 4.4 & $97 \%$ & $49 \%$ \\
\hline 7.24 & 59 & 309 & 25.3 & 139 & 4.1 & 1.04 & 197 & 2.8 & $100 \%$ & $49 \%$ \\
\hline
\end{tabular}

On byepass ABG \& electrolytes

\begin{tabular}{|l|l|l|l|l|l|l|l|l|l|l|}
\hline pH & pCO2 & PO2 & HCO3 & Na & K & Ca & Gluc & lactate & SPO2 & Hct \\
\hline 7.34 & 44 & 322 & 23.7 & 139 & 4.5 & 1.00 & 171 & 1.8 & $100 \%$ & $44 \%$ \\
\hline 7.26 & 54 & 134 & 24.2 & 136 & 4.9 & 1.12 & 256 & 4.8 & $99 \%$ & $39 \%$ \\
\hline 7.32 & 48 & 333 & 24.7 & 135 & 4.7 & 1.16 & 183 & 3.9 & $100 \%$ & $34 \%$ \\
\hline 7.32 & 48 & 268 & 24.7 & 138 & 4.3 & 1.16 & 177 & 4.3 & $100 \%$ & $32 \%$ \\
\hline 7.42 & 36 & 209 & 23.4 & 137 & 4.9 & 1.14 & 169 & 3.8 & $100 \%$ & $33 \%$ \\
\hline 7.51 & 33 & 137 & 26.3 & 137 & 5.0 & 1.08 & 178 & 3.2 & $99 \%$ & $31 \%$ \\
\hline
\end{tabular}

Post byepass ABG \& electrolytes

\begin{tabular}{|l|l|l|l|l|l|l|l|l|l|l|}
\hline pH & pCO2 & PO2 & HCO3 & Na & K & Ca & Gluc & lactate & SPO2 & Hct \\
\hline 7.38 & 38 & 174 & 22.5 & 144 & 3.3 & 0.82 & 229 & 3.7 & $100 \%$ & $33 \%$ \\
\hline 7.37 & 42 & 158 & 24.3 & 144 & 3.6 & 0.92 & 176 & 3.2 & $99 \%$ & $33 \%$ \\
\hline
\end{tabular}

Vital parameters at various time intervals:

Pre byepass:

\begin{tabular}{|l|l|l|l|l|l|}
\hline TIME & $0.5 \mathrm{hr}$ & $1 \mathrm{hr}$ & $1.5 \mathrm{hr}$ & $2 \mathrm{hr}$ & $2.5 \mathrm{hr}$ \\
\hline Temp & $37.1^{\circ} \mathrm{C}$ & $38.5^{\circ} \mathrm{C}$ & $39.7^{\circ} \mathrm{C}$ & $39.9^{\circ} \mathrm{C}$ & $38.1^{\circ} \mathrm{C}$ \\
\hline ETCO2 & $37 \mathrm{mmHg}$ & $46 \mathrm{mmHg}$ & $67 \mathrm{mmHg}$ & $92 \mathrm{mmHg}$ & $58 \mathrm{mmHg}$ \\
\hline HR & $68 / \mathrm{min}$ & $88 / \mathrm{min}$ & $110 / \mathrm{min}$ & $126 / \mathrm{min}$ & $101 / \mathrm{min}$ \\
\hline BP & $138 / 90 \mathrm{mmHg}$ & $124 / 78 \mathrm{mmHg}$ & $125 / 87 \mathrm{mmHg}$ & $130 / 92 \mathrm{mmHg}$ & $124 / 85 \mathrm{mmHg}$ \\
\hline
\end{tabular}


minutes. Sweep gas flow rate $(\mathrm{L} / \mathrm{min})$ was kept double the blood flow rate $(\mathrm{L} / \mathrm{min})$. Haemofiltration was used to correct the raised lactate levels, decrease the levels of inflammatory mediators and to correct hemodilution. Levels of calcium and potassium were kept within normal limits. Hypothermia was maintained throughout the byepass period. Total byepass time was $1.5 \mathrm{hrs}$. Patient was weaned gradually from the byepass. Rewarming was carried out very slowly. At the end, patient was neither reversed nor extubated and was shifted to cardiac icu on dobutamine infusion @ $3.0 \mathrm{mcg} / \mathrm{kg} / \mathrm{hr}$, inj propofol@100mg/hr, inj esmolol @ 0.20 mcg $/ \mathrm{kg} / \mathrm{hr} \&$ inj NTG @ 2mcg/ $/ \mathrm{kg} / \mathrm{min}$. Postoperative course remained uneventful and after $6 \mathrm{hrs}$ of stabilisation in icu with constant monitoring of blood gases, electrolytes, urine output \& body temperature patient was extubated successfully. Adequate hydration and urine output @1$2 \mathrm{ml} / \mathrm{kg} / \mathrm{hr}$ was maintained. All investigations (CBC, KFT, LFT, Coagulogram, ABG \& electrolytes) done postoperatively were within the normal limits.

The patient was referred to genetic centre for counselling and discharged after 7 days of stay in ICU with full instructions \& counselling to the family members.

\section{DISCUSSION}

Malignant hyperthermia (MH) is characterized by hyperthermia, hypercarbia, increased oxygen consumption, acidosis, tachycardia, tachypnea, rigidity and rhabdomyolysis. We made diagnosis of malignant hyperthermia on the basis of clinical features. The possibilities of neuroleptic malignant syndrome and serotonin syndrome were excluded, as patient was not on any neuroleptic or antidepressant drugs. Pheochromocytoma and thyrotoxic crises were less likely as suggested by normal history, examination and investigations. Also the degree of $\mathrm{CO}_{2}$ production and metabolic acidosis is much lower in these disorders. ${ }^{[1]}$ The agents administered for induction and maintenance of anaesthesia in our case included morphine, fentanyl, midazolam, vecuronium, sevoflurane and isoflurane. Isoflurane has been reported to be one of the potent triggering agents of malignant hyperthermia. ${ }^{[2]}$ Patients who are susceptible to $\mathrm{MH}$ may have neuromuscular disorders. ${ }^{[3,4]}$ A positive family history of malignant hyperthermia in a first-degree relative is a strong indicator of MH susceptibility. Our patient had no neuromuscular disease and his family members had successfully undergone surgeries under general anesthesia. Management of MH syndrome requires early detection and prompt intervention. Dantrolene is the drug of choice for reversing malignant hyperthermia syndrome. Dantrolene inhibits the release of calcium from sarcoplasmic reticulum by binding to the ryanodine receptors, thereby halting the uncontrolled muscle contractions. ${ }^{[5]}$ The mortality rate from $\mathrm{MH}$ was reduced from $80 \%$ to less than $10 \%$ following the development of dantrolene. ${ }^{[6]}$ Dantrolene is not available in our hospital but we were able to rescue our patient from the crisis with prompt diagnosis and quick aggressive supportive measures with the help of a trained professional team. Patients recovering from MH may develop complications as a consequence of hyperthermia and excessive muscle breakdown. Many complications are recorded, the most common being the neurological, cardiac dysfunctions, pulmonary edema, disseminated intravascular coagulation, renal and hepatic dysfunctions ${ }^{[7]}$ As myoglobinemia due to excessive muscle destruction increases the risk of kidney injury, urine output should be maintained greater than $2 \mathrm{ml} / \mathrm{kg} / \mathrm{hr}$. ${ }^{[8]}$ Successful surgery of our patient with $\mathrm{MH}$ non-triggering general anesthesia was carried out and patient had no intra operative complications on cardiopulmonary byepass. The presenting symptoms were an increase in the $\mathrm{ETCO}_{2}$, body temperature and tachycardia,both of which are nonspecific for $\mathrm{MH}$. We found no cause of hypercapnia or tachycardia after exploring various possible causes. It is well known that an abrupt increase in body temperature can be an important sign of $\mathrm{MH}^{[9]}$ However, it is a relatively late sign. Therefore an unexplained elevation in the $\mathrm{ETCO}_{2}$ can be a sensitive and the earliest symptom of $\mathrm{MH}^{[10]}$. There is no center available in India where in vitro halothane caffeine contracture test is performed to confirm the diagnosis in suspected cases. We strongly endorse the use of end tidal $\mathrm{CO}_{2}$ and temperature monitoring during anesthesia as hypercarbia and rapidly increasing temperature are the most common clinical signs of acute malignant hyperthermia. ${ }^{[1]}$ Early detection and aggressive supportive management can save the patient without major complications.

\section{REFERENCES}

1. Rosenberg H, Brandom BW, Sambuughin N. Malignant hyperthermia and other inherited disorders. In: Barash PG, Cullen BF, Stoelting RK, 
Cahalan MK, Stock MC, editors. Clinical Anesthesia. 2nd Philadelphia: Lippincott Williams \&Wilkins; 2009. p. 598-621.

2. McGuire N, Easy WR. Malignant hyperthermia during isoflurane anaesthesia. Anaesthesia. 1990 Feb; 45(2):124127.

3. Klingler W, Rueffert H, Lehmann-Horn F, Girard T, Hopkins PM. Core myopathies and risk of malignant hyperthermia. Anesth Analg. 2009; $109: 116773$. doi:10.1213/ ANE. 0b013e3181b5ae2d.

4. Benca J, Hogan K. Malignant hyperthermia, coexisting disorders, and enzymopathies: risks and management options. Anesth Analg. 2009; 109:104953. doi: 10.1213/ ane. 0b013e3181adca28.

5. Zhao F, Li P, Chen SR, Louis CF, Fruen BR. Dantrolene inhibition of ryanodine receptor $\mathrm{Ca} 2+$ release channels: Molecular mechanism and isoform selectivity. J Biol Chem. 2001;276:138106
6. Rosenberg H, Fletcher JE. An update on the malignant hyperthermia syndrome. 1994 Nov; 23(6 Suppl):84-97.

7. Nasir KK, Zafar AB, Mansoor F, Mushtaq S, Ahmad J, Khan IM. Malignant hyperthermia. J Coll Phys Surg Pak. 2004; 14:39-40.

8. Bosch X, Poch E, Grau JM. Rhabdomyolysis and acute kidney injury. N Engl J Med. 2009;361:6272

9. Kim DC, Lim HR, Han YJ. Early recognition of malignant hyperthermia with capnography. Korean J Anesthesiol. 2002; 43:667672.

10. Baudendistel L, Goudsouzian N, Cote' C, Strafford M. End-tidal CO2 monitoring. Its use in the diagnosis and management of malignant hyperthermia. Anaesthesia. 1984; 39:10001003.

11. Nelson P, Litman RS. Malignant hyperthermia in children: an analysis of the North American malignant hyperthermia registry. Anesth Analg. 2014; 118:369-74. 